\title{
Dominance-subordination polarity in early-handled and nonhandled rats ${ }^{1}$
} GILBERT BECKER, DEPARTMENT OF PSYCHOLOGY,
UNIVERSITY OF MANITOBA, Wimipcg, Canada AND IRBY J.
GAUDET, DEPARTMENT OF PSYCHOLOGY, AUBURN UNIVERSITY, Auburn, Alabama

Early-handled and nonhandled rats were paired with members of their own group in adulthood and permitted to compete for food under deprivation conditions. Polarity scores, defined as the winners' proportion-of-time-at-the-food-container scores minus 50. were higher in the handled group. These results were interpreted in terms of interactions between carly-stimulation effects and reinforcement-contingency effects

Previous studies have indicated that the learning of socialdominance and subordination habits during adulthood can be facilitated by either tactual stimulation (Mezei \& Rosen, 1960 Rosen, 1958) or electrical stimulation (Becker, 1965) administered during the developmental period. In those studies, earlystimulated Ss were paired with control Ss to determine whether group differences in social status would emerge. No attempt has been made, as far as the authors know, to pair Ss given the same treatment, and to look for treatment differences in terms of the tendency to share the object of competition on a 50-50 basis (low polarity) vs the tendency to assume a complete superordinatesubordinate relationship (high polarity). The present study sought to examine the effects of infantile stimulation on dominancesubordination polarity in the adult albino rat.

Subjects. The Ss were 44 male rats of the Sprague-Dawley strain. They were born of timed pregnants which were delivered to our laboratory by Dan Rolfsmeyer Co. during the early part of the second trimester of gestation, and placed in individual cages.

Apparatus. The apparatus used for testing dominance-subordination polarity has been described in detail and illustrated elsewhere (Becker, 1965). It is basically a rectangular box made of wood with a removable Plexiglas top. A platform extends from each end on which a home cage can be secured on its side. When the guillotine door at the relevant end of the box is raised, the rat in the cage has access to the contents of a plastic cylindrical container screwed to the center of the floor.

Procedure. Pups in the even-numbered cages were systematically handled once each day on Days 9 through 19. The handling procedure consisted of the sequence of placing $S$ in one hand, stroking on the head and neck 12 times with the thumb, tossing into the air twice, shaking by the tail for a few seconds, and placing in a covered cardboard box for $2 \mathrm{~min}$ before returning to the home cage. Pups in the odd-numbered cages were left untouched. Ss were separated from their mothers on Day 25 and placed into individual cages. Of the two treatment groups, 22 handled and 22 control males were selected at random for testing.

The test-box-habituation procedure began on Day 141 and consisted of placing a home cage, with $S$ inside, laterally on one of the cage platforms. $S$ was then permitted to pass through the raised door, explore the box, and eat the wet mash placed in the food container. A 15-g-per-day schedule was maintained during the habituation period, which lasted 11 days. All Ss during this period reached the criterion of a 6 sec latency in reaching the food container.

Competitions began on Day 152 at which time the food-deprivation schedule was changed to $12 \mathrm{~g}$ per day. The same two Ss making up each pair were allowed to compete for food over 155 -min trials, one trial per day. On a given competition, two home cages (with $S$ inside) were placed one on each cage platform. The two doors were raised simultaneously, permitting each $S$ to approach the food container with equal advantage and compete for the wet mash available to only one $S$ at a time because of the small diameter $\left(1 \frac{1}{4}\right.$ in) of the food container. A separate stop watch was used for each $S$ whose tail was colored to faciliate recognition.

Data Treatment. The accumulated-time scores were converted into percentages indicating the amount of time $S$ spent eating at the container relative to the total amount of time both Ss spent eating at the container. The polarity score was defined as the absolute difference between the winner's percentage score (or the loser's) and 50. Thus. where the winner's percentage score was 70 (and the loser's, 30), the polarity score was $70-50=20$. Polarity scores, then, ranged from zero (where the Ss' percentage scores are 50 and 50) to 50 (where the Ss' percentage scores are 100 and zero). For statistical purposes, the 15 trials were collapsed into three blocks of five trials each to form the basis for a 2 by 3 (treatments by blocks) mixed factorial analysis of variance.

Results. The results are summarized in Table 1 and Fig. 1. The treatment differences are highly significant $(F=18.17, \mathrm{df}=1 / 20$, $\mathrm{p}<.0005$ ). While the polarity scores in the two groups were similar during the early trials, they gradually diverged from each other. Because the mutual divergence was more or less symmetri$\mathrm{cal}$, the trial-blocks effect is nil. The treatments by blocks interaction effect is highly significant $(F=13.20$, df $=2 / 40, p<$ .0005 ). In comparing Blocks 1 and 3 , we find a highly significant difference in polarity scores in the handled group $(A=.126, \mathrm{df}=$ $10, p<.001)$ and in the control group $(A=.118, d f=10, p<$ $.001)$. The two groups differed also in polarity-score homogeneity. The differences reached significance only in Blocks 2 and $3(\mathrm{~F}=$ 4.07, $\mathrm{df}=10 / 10, \mathrm{p}<.05$ and $\mathrm{F}=7.05, \mathrm{df}=10 / 10, \mathrm{p}<.01$, respectively).

Discussion. One explanation for the central-tendency difference seems to be generalizable from an explanation of the status superiority of earlystimulated Ss paired with controls. Presumably, early-stimulated Ss, whether in homogeneous or heterogeneous pairings, deliver a greater number of noxious stimuli and/or deliver stimuli that are more potent and/or are able to tolerate similar stimuli emanating from the opponent for a longer period before switching from a counter-aggression response to a subordination response (Becker. 1963, pp. 37-40). Where two early-stimulated Ss are paired. it seems that when one rat finally does switch and assumes a subordination response, such a switch is more reinforcing in view of his opponent's ability to deliver more blows, etc. In short, polarity seems to be a function of how well the subordinate $\mathrm{S}$ learns his role; or. in different terms, polarity seems to be a function of the values of the various parameters of the learning situation: number of drive stimuli presented each trial, intensity of such drive stimuli. and number of trials over which such drive stimuli are presented.

Why did the control Ss show a drop in polarity over trials? One explanation is that whatever initial differences in intimidation existed diminished via the lack of relatively high-level aversive and counter-aversive stimuli presumably delivered by the handled Ss. The two explanations

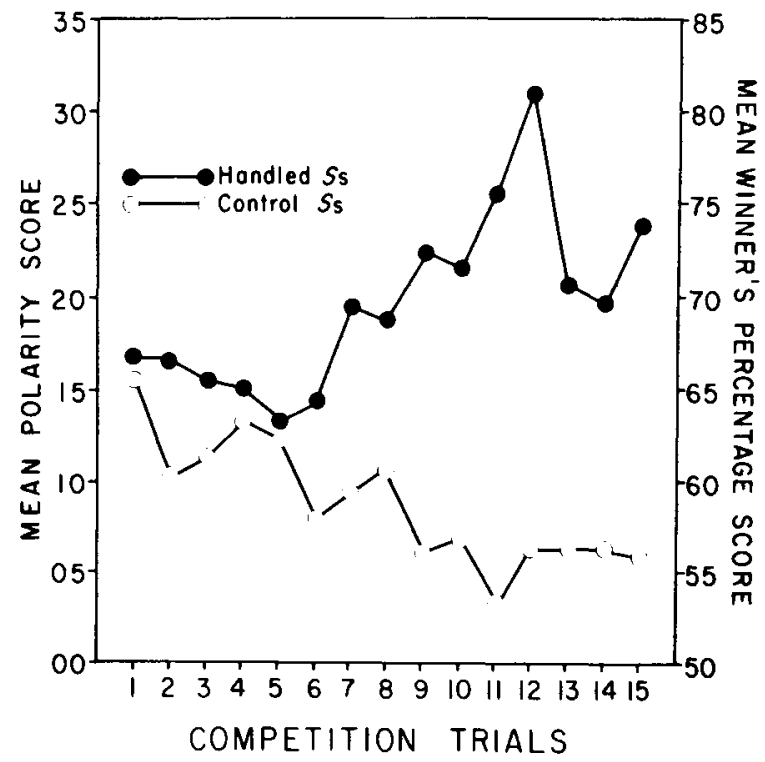

Fig. 1. Polarity score as a function of competition trial. 
Table 1

Polarity Scores Across Blocks

\begin{tabular}{|c|c|c|c|c|c|c|}
\hline & \multicolumn{2}{|c|}{ Block 1} & \multicolumn{2}{|c|}{ Block 2} & \multicolumn{2}{|c|}{ Block 3} \\
\hline & $\mathrm{M}$ & SD & $\mathbf{M}$ & SD & M & $\mathrm{SD}$ \\
\hline Handled Ss & 15.32 & 6.59 & 19.31 & 11.91 & 24.23 & 7.09 \\
\hline Control Ss & 12.51 & 3.83 & 8.20 & 5.90 & 5.47 & 2.67 \\
\hline All Ss & 13.91 & 5.57 & 13.76 & 10.92 & 14.85 & 10.80 \\
\hline
\end{tabular}

presented thus far, taken together, could assume some intermediate level of expectation of aggression, which through subsequent delivery of highly- or lowly-aversive stimuli, is confirmed or disconfirmed, respectively. In the former case the subordinate $\mathrm{S}$ learns his role well and beyond expectation, and in the latter case the subordinate $\mathrm{S}$ learns his role poorly and below expectation.

The variance differences are not surprising in view of similar differences reported where a noxious stimulus is administered to one group and not the other. Presumably, the greater variability of the treated group reflects the differential susceptibility of Ss to the effects of treatment. An alternative explanation relates to the fact that there is a floor (polarity $=$ zero) and a ceiling (polarity $=50$ ) on the polarity scale. Consequently, group tendencies toward one extreme or the other would tend to reflect more homogeneous scores than those tendencies toward the center.

\section{REFERENCES}

BECKER, G. Social dominance and subordination in the rat as a function of postweaning electrical stimulation. J. genet. Psychol., 1965, 107, 349-369.

BECKER, G. Social dominance and subordination in the rat: Effects of postweaning electrical stimulation. Unpublished doctoral dissertation, University of Pittsburgh, 1963.

MEZEI, T. C., \& ROSEN, J. Dominance behavior as a function of infantile stimulation in the rat. Arch. gen. Psychiat., 1960, 3, 53-56.

ROSEN, J. Dominance behavior as a function of post-weaning gentling in the albino rat. Canad. J. Psychol., 1958, 12, 229-234.

\section{NOTE}

1. This study was supported in part by Grant No. 05-195-64 made available by the Graduate Studies Expansion Fund of the University of Manitoba. 